\title{
Wykaz skrótów bibliograficznych
}

AdREssBuch 1902: Adressbuch für Berlin und seine Vororte. Unter Benutzung amtlicher Quellen, Hg. August ScherL, cz. I, Berlin 1902.

ArszyŃski 2006: Marian Arszyński, Steinbrecht Conrad, hasło [w:] Polski słownik biograficzny konserwatorów zabytków, z. 2, Poznań 2006, s. 244-246.

BeDEKER GRUCZEŃSKI 2007: Bedeker gruczeński, red. Jadwiga LuteREK-CHOLEWSKA, Gruczno 2007.

BIEŃKowski 2012: Andrzej BIEŃKowskI, Ostatni wiejscy muzykanci, Warszawa 2012.

BIRECKI 2007: Piotr BIRECKI, Sztuka luterańska na ziemi chełmińskiej od drugiej połowy XVI do pierwszej ćwierci XVIII wieku, Torun 2007.

Biskup 2007: Radosław Biskup, Das Domkapitel von Samland (1285-1525), Toruń 2007.

Biskup / CzyżAK 2012: Radosław Biskup, Marta CzyżAK, Biskup sambijski Jan Clare $z$ Torunia (1319-1344) i jego księgozbiór, „Folia Toruniensia”, 12, 2012, s. 15-28.

BlaschKe 1973: Karlheinz Blaschke, Studien zur Frühgeschichte Städtewesens in Sachsen, [w:] Festschrift für Walter Schlesinger, 1, Hg. Helmut BeumanN, („Mitteldeutsche Forschungen“ 74/I), Köln-Wien 1973, s. 333-381.

BorcowskI 2006: Zbigniew BorcowskI, Stanowisko 5 w ujęciu funkcjonalno-chronologicznym, [w:] Archeologia Gdańska, 1, red. Henryk PANER, Gdańsk 2006, s. 89-104.

CIEŚLAK 1992: Katarzyna CIEŚLAK, Kościót - cmentarzem. Sztuka nagrobna w Gdańsku (XV-XVIII w.). „Długie trwanie” epitafium, Gdańsk 1992.

CIEŚLAK 1993: Katarzyna CIEŚLAK, Epitafia obrazowe w Gdańsku (XV - XVII w.), Gdańsk 1993.

Cieślak 1998: Katarzyna CIEślak, Tod und Gedanken. Danziger Epitaphien vom 15. bis zum 20. Jahrhundert, Lüneburg 1998.

Codex Manesse 1992: Codex Manesse. Die Miniaturen der Großen Heidelberger Liederhandschrift, Hg. Ingo F. WaltheR, Frankfurt am Main 1992.

Czarnecki 1990: Kazimierz CzARnecki, Płockie życie artystyczne w latach 1900-1939, Płock 1990.

CzyżaK / Wagner 2013: Marta Czyżak, Arkadiusz Wagner, Odnaleziony modlitewnik biskupa chełmińskiego Wikbolda Dobilsteina, „Zapiski Historyczne”, 78, 2013, z. 3, s. 99-116.

Die Ausgrabungen zu Olympia 1877: Die Ausgrabungen zu Olympia, 2: Übersicht der Arbeiten und Funde vom Winter und Frühjahr 1876-1877, red. Ernst CurTius, Friedrich AdLER, Gustav HIRSCHEELD, Berlin 1877. 
Die Statuten [1890]: Die Statuten des Deutschen Ordens nach den ältesten Handschriften, Hg. Max Perlbach, Halle 1890.

DobBERT 1899: Eduard DoBbERT, Bauakademie, Gewerbeakademie und Technische Hochschule bis 1884. Historische Skizze, Berlin 1899.

Dobrowolski 1964: Tadeusz DoBrowolski, Nowoczesne malarstwo polskie, Wrocław-Warszawa-Kraków 1964.

Drost 1959: Willi Drost, Kunstdenkmäler der Stadt Danzig, 3: Sankt Nikolai, St. Joseph, Königliche Kapelle, Hl. Leichnam, St. Salvator, Stuttgart 1959.

Dzieje sztuki ToRunia 2009: Anna BŁAżejewska, Katarzyna Kluczwajd, Bogusław Manseeld, Elżbieta PIleckA, Jacek Tylicki, Dzieje sztuki Torunia, Toruń 2009.

Evans 1795: Oliver Evans, The Young Mill-wright and millers' guide, Philadelphia 1795. Frodl 1966: Walter Frodu, Pojęcia i kryteria wartościowania zabytków: ich oddziaływanie na praktykę konserwatorska, przekł. Marian ArszyńskI, („Biblioteka Muzealnictwa i Ochrony Zabytków. Seria B” 13), Warszawa 1966.

Frodl-Kraft 1963: Eva Frodl-Kraft, Gotische Glasmalereien aus dem Kreuzgang in Klosterneuburg, („Klosterneuburger Kunstschätze“ 3), Klosterneuburg 1963.

Getka-Pesta 2012: Sylwia Getka-Pesta, Stan badań nad Ottarzem Grudziądzkim, „Rocznik Grudziądzki”, 20, 2012, s. 115-135.

GoŁuńSKa 2013: Honorata GoŁuńska, Dekoracje kamienic Ernsta Petersa w Bydgoszczy z początku XX wieku, [mps], Uniwersytet Mikołaja Kopernika w Toruniu, Toruń 2013 (dostęp - Archiwum Prac Dyplomowych UMK).

Haftka 1999: Mieczysław Haftka, Zamki krzyżackie w Polsce. Szkice z dziejów, Malbork-Płock 1999.

Harasimowicz 1992: Jan Harasimowicz, Mors Janua Vitae. Śląskie epitafia i nagrobki wieku reformacji, Wrocław 1992.

Hauke 1967: Karl Hauke, Steinbrecht Conrad, hasło [w:] Altpreußische Biografie, Hg. Christian Krollmann, Kurt Forstereuter, Friez Gause, 2, Maltiz-Z, Marburg/ /Lahn 1967, s. 695.

HeIse 1889: Johannes HeIse, Die Bau- und Kunstdenkmäler der Provinz Westpreußen, H. 6-7: Der Kreis Thorn, Danzig 1889.

JakUBOwSKA 2001: Bogna JAKUBOwSKA, Renesansowa galeria konterfektów oliwskich i jej źródło pisane, [w:] Praeterita Posteritati. Studia z historii sztuki i kultury ofiarowane Maciejowi Kilarskiemu, red. Mariusz MIERzwiŃskI, Malbork 2001, s. $147-178$.

JakUBOwSKA 2003: Bogna JAKUBOWsKa, In pictura et in scriptura. Treści ideowe renesansowej galerii fundatorów i dobrodziejów Oliwy, [w:] Studia z historii sztuki i kultury Gdańska i Europy Pólnocnej. Prace poświęcone pamięci doktor Katarzyny Cieślak, red. Jacek Friedrich, Edmund KIzIK, Gdańsk 2003, s. 57-89.

JASIŃSKI 1974: Kazimierz JASIŃSKI, Z problematyki trzynastowiecznego Gdańska. Kościoły gdańskie, „Zapiski Historyczne“, 39, 1974, z. 3, s. 37-67.

Jası́́skI 1985a: Kazimierz JAsIŃSKI, Chronologia kościołów gdańskich XII i XIII w. Uwagi metodyczne, cz. I, „Zapiski Historyczne“, 50, 1985, z. 1, s. 55-77.

JasIŃSKI 1985b: Kazimierz JASIŃSKI, Chronologia kościołów gdańskich XII i XIII w. Uwagi metodyczne, cz. II, „Zapiski Historyczne“, 50, 1985, z. 2, s. 70-89. 
JóźwIAK / TRUPINDA 2012: Sławomir JóźwIAK, Janusz TRUPINDA, Krzyżacki zamek komturski w Grudziądzu w średniowieczu na podstawie źródeł pisanych. Chronologia powstania i układ przestrzenny, [w:] ZAMEK w GRUDziąDZU 2012, s. 49-71.

KalinowsKi 2004: Lech Kalinowski, Malarstwo witrażowe, [w:] Malarstwo gotyckie w Polsce, red. Adam Stanisław Labuda, Krystyna Secomska, 1: Synteza, (Dzieje Sztuki Polskiej" 2/3), Warszawa 2004, s. 185-214.

KarŁowska-Kamzowa 1988: Alicja KarŁowska-Kamzowa, Dekoracje malarskie gotyckich rękopisów iluminowanych ze zbiorów Biblioteki Uniwersyteckiej w Toruniu, „Studia o Działalności i Zbiorach Biblioteki Uniwersytetu Mikołaja Kopernika”, 4, 1988, s. 113-147.

KarŁowsKa-Kamzowa 1990: Alicja KarŁowsKa-Kamzowa, Malarstwo miniaturowe, [w:] Jerzy DomasŁowski, Alicja KarŁowska-Kamzowa, Adam S. Labuda, Malarstwo gotyckie na Pomorzu Wschodnim, Warszawa-Poznań 1990, s. 178-218.

Katalog 2016: Katalog rękopisów średniowiecznych Biblioteki Uniwersyteckiej w Toruniu, oprac. Marta CzyżaK, współpr. Monika Jakubek-Raczkowska, Arkadiusz Wagner, Toruń 2016.

Kluge i In. 1963: Tadeusz Kluge, Leopold SteEAŃski, Witold Steinborn, Stanisław WoRoch, Technologia młynarstwa. Część pierwsza (dla klas II i III), Warszawa 1963.

Kolendo-Korczak 2009: Katarzyna Kolendo-Korczak, Propaganda reform burmistrza Henryka Strobanda w dekoracji Sali Rady z 1603 r. w ratuszu staromiejskim w Toruniu, „Zapiski Historyczne”, 74, 2009, z. 3, s. 37-60.

Kolendo-Korczak 2014: Katarzyna Kolendo-Korczak, Praecepta politica $w$ toruńskim ratuszu. Niezachowany cykl malowideł z Sali Rady z 1603 roku i jego europejski kontekst, Warszawa 2014.

Krassowski 1973: Witold KrassowskI, Aestetyczna ozdoba w architekturze 2 pol. XIX wieku, [w:] Sztuka 2 połowy XIX wieku. Materiały Sesji Stowarzyszenia Historyków Sztuki, Łódź, listopad 1971, red. Teresa Hrzankowska, Warszawa 1973, s. 137-147.

KRAwCZYK 2013: Janusz KRAwCZyK, Dialog z tradycją w konserwatorstwie - koncepcja zabytkoznawczej analizy wartościujacej, „Acta Universitatis Nicolai Copernici. Zabytkoznawstwo i Konserwatorstwo", 44, 2013, s. 507-529.

Kronika oliwska [2008]: Kronika oliwska. Źródło do dziejów Pomorza Wschodniego z połowy XIV wieku, przekł. Dominika PIETkIEwICz, wstęp i komentarz Błażej ŚLIwiŃSKI, Malbork 2008.

KrzyŻANOWSKI 1958: Lech KRZyŻANowskI, Plastyka nagrobna Wilhelma van den Blocke, „Biuletyn Historii Sztuki“, 20, 1958, nr 3-4, s. 270-297.

Kupric 1957: Âkov Nikolaevič KupRIc, Teoria i technologia przemiału zboża, Warszawa 1957.

Kurmann-Schwarz 2006: Brigitte Kurmann-Schwarz, Malerei mit schwarzer Farbe auf leuchtend buntem Glas: der Stil der Glasmalerei in seiner Beziehung zu den anderen Gattungen der Malerei, [w:] Stilfragen zur Kunst des Mittelalters. Eine Einführung, Hg. Bruno KleIN, Bruno BoeRner, Berlin 2006, s. 123-136.

Kwaskowski 1975: Stanisław Kwaskowski, Teatr w Toruniu 1920-1939, Gdańsk-Bydgoszcz 1975. 
LASKOWSKI 2012: Andrzej LASKOWSKI, „Sibi et posteritati”. Autoprezentacja i reklama w środowisku architektów, budowniczych i inżynierów w Galicji u schyłku XIX i na poczq̨tku XX wieku, „Kwartalnik Architektury i Urbanistyki. Teoria i Historia”, 57, 2012, z. 1, s. 35-54.

LE vitRAIL ET LES TRAItÉs 2008: Le vitrail et les traités du Moyen Âge à nos jours. Actes du XXIII e colloque international du Corpus Vitrearum, Tours 3-7 juillet 2006, ed. Karine Boulangser, Michel HÉRold, Bern 2008.

LEKSYKON Liturgi 2006: Leksykon liturgii, oprac. Bogusław NADOLSKI, Poznań 2006.

Lingenberg 1982: Heinz Lingenberg, Die Anfänge des Klosters Oliva und die Entstehung der deutschen Stadt Danzig, („Kieler Historische Studien“ 30), Stuttgart 1982.

LipoŃSKA-SAJDAK 2002: Jadwiga LipońSKA-SAJDAK, Czas siewu..., [w:] LIPOŃSKA-SAJDAK / / SzczypKa-GWiazda / KRYPCZyK 2002, s. 3-11.

LIPOŃSKA-SAJDAK / SZCZYPKA-GWIAZDA / KRYPCZYK 2002: Jadwiga LiPOŃSKA-SAJDAK, Barbara SzczypKa-GwiAzda, Aleksandra KrypczyK, Sztuka pogranicza na Górnym Ślacku w dobie II Rzeczypospolitej, Katowice 2002.

Lustracja wojewóDzTw [2009]: Lustracja województw Prus Królewskich 1765, 2, Województwo chełmińskie, cz. 2, Ziemia chełmińska, wyd. Jerzy DygdaŁA, Torun 2009

Manikowska 2000: Halina Manikowska, Princeps fundator $w$ przedlokacyjnym Wrocławiu. Od Piotra Włostowica do Henryka Brodatego, [w]: Fundacje i fundatorzy w średniowieczu i epoce nowożytnej, red. Edward Opaliński, Tomasz Wiślicz, Warszawa 2000, s. 37-57.

Manseeld 2009: Bogusław Manseeld, Sztuka od XIX do początku XXI wieku, [w:] DzIEJE SZTUKI TORUNIA 2009, s. 365-509.

MarszaŁkowski 2013: Mateusz MarszaŁkowski, Toruński rękopis Statutów zakonu krzyżackiego. Praca magisterska pod kierunkiem Moniki JAKUBEK-RAczKowskIEJ, Instytut Zabytkoznawstwa i Konserwatorstwa UMK, [mps], Toruń 2013 (dostęp Sekcja Rękopisów BUMK oraz Archiwum Prac Dyplomowych UMK).

MeIssner 1713: Theodor Benjamin MeIssner, Das edle Danzig oder Danziger Chronik, 1713.

MeIssner 1723: Theodor Benjamin MeIssner, Das kirchenreiche Dantzig, [rps], 1723 (dostęp - Deutsche Staatsbibliothek z Berlinie Ms. Boruss., Fol. 279).

Mentzel-Reuters 2003: Arno Mentzel-Reuters, Arma spiritualia: Bibliotheken, Bücher und Bildung im Deutschen Orden, Wiesbaden 2003.

MichaŁowski 1993: Roman MichaŁowski, Princeps fundator. Studium z dziejów kultury politycznej w Polsce X-XIII wieku, Warszawa 1993.

MichaŁowski 1994: Roman MichaŁowski, Kościól Św. Mikołaja we wczesnopiastowskich ośrodkach rezydencjonalnych, [w:] Społeczeństwo Polski średniowiecznej. Zbiór studiów, 6, red. Stefan K. KuCZyŃskI, Warszawa 1994, s. 63-74.

MŁynarska-Kaletynowa 1978: Marta MŁynarska-Kaletynowa, W sprawie poczq̨tków miast saskich w XII w. (Uwagi na marginesie artykułu K. Blaschke 'go), „Kwartalnik Historii Kultury Materialnej“, 26, 1978, z. 1, s. 77-82.

Момот / WasIK 2013: Agata Mомот, Bogusz WASIK, Badania archeologiczno-architektoniczne zamku krzyżackiego w Kowalewie Pomorskim w roku 2013 roku, [mps], Toruń 2013 (dostęp - Instytut Archeologii UMK w Toruniu). 
Momot / WasiK / Wiewióra 2014: Agata Momot, Bogusz WasiK, Marcin WiewióRA, Zamek krzyżacki w Papowie Biskupim. Nowe odkrycia i nowe interpretacje, „Rocznik Grudziądzki", 22, 2014, s. 65-98.

NiEMATERIALNE DZIEDZICTwo 2013: Niematerialne dziedzictwo kulturowe: źródła wartości - ochrona, red. Jan ADAMOwSKI, Katarzyna SMYK, Lublin-Warszawa 2013.

OpIS KRóLEWSZCZyZN [1938]: Opis królewszczyzn w województwach chełmińskim, pomorskim i malborskim w roku 1664, wyd. Józef Paczkowski, Torun 1938.

Paner 2006: Henryk Paner, Archeologia gdańska w latach 1988-2005, [w:] Archeologia Gdańska, 1, red. Henryk PANER, Gdańsk 2006, s. 68-70.

PëSLER 1995: Ralf G. PÄsleR, Zur Herkunft von Handschriften und alten Druken der ehemaligen Staats- und Universitätsbibliothek Königsberg. Ernst Kuhnerts Provenienzregister, „BuF“, 3, 1995, s. 39-48.

PÄSlER 2000: Ralf G. PÄSLER, Katalog der mittelalterlichen deutschsprachigen Handschriften der ehemaligen Staats- und Universitätsbibliothek Königsberg. Nebst Beschreibung der mittelalterlichen deutschsprachigen Fragmente des ehemaligen Staatsarchivs Königsberg, München 2000.

PÄSlER 2003: Ralf G. PÄSlER, Deutschsprachige Sachliteratur im Preußenland bis 1500. Untersuchungen zu ihrer Überlieferung, Köln-Weimar-Wien 2003.

PëSLER 2004: Ralf G. PÄSLER, Die Handschriftensammlungen der Staats- und Universitätsbibliothek, der Stadtbibliothek und des Staatsarchivs Königsberg. Mit einem Exkurs zur mittelalterlichen Bibliotheksgeschichte der Stadt und Anhängen [w:] Königsberger Buch- und Bibliotheksgeschichte, red. Axel E. Walter, Köln 2004, s. 235-246.

Poradnik meynarza 1960: Poradnik młynarza, red. Henryk Lisiecki, Warszawa 1960.

Powalisz 1956: Maria Powalisz, Średniowieczne witraże: Torunia, Włocławka i Chełmna, praca magisterska, Uniwersytet Adama Mickiewicza w Poznaniu, [mps], Poznań 1956.

Regensburger Buchmalerei 1987: Regensburger Buchmalerei von frühkarolingischer Zeit bis zum Ausgang des Mittelalters. Ausstellung der Bayerischen Staatsbibliothek München und der Museen der Stadt Regensburg, Hg. Florentine MüTHERICH, Karl Dachs, München 1987.

Rogalski 1986: Bogumił RogalsKI, Komturski gotycki zamek krzyżacki w Kowalewie na tle ówczesnej architektury obronnej zakonu, [w:] Dzieje Kowalewa Pomorskiego, red. Jerzy Danielewicz, Bydgoszcz 1986, s. 57-95.

Rymar 1995: Edward RyMar, Rodowód książąt pomorskich, Szczecin 1995.

Rymar 2003: Edward Rymar, Rodowód ksiażąt pomorskich. Suplement, Gdańsk 2003.

Schmidt 2005: Gerhard Schmidt, Malerei der Gotik. Fixpunkte und Ausblicke, 1: Malerei der Gotik in Mitteleuropa, Graz 2005.

Semrau 1892: Arthur Semrau, Die Grabdenkmäler der Marienkirche zu Thorn, („Mitteilungen des Coppernicus-Vereins für Wissenschaft und Kunst zu Thorn“ 7), Thorn 1892.

Sieradzan 2011: Wiesław Sieradzan, Bernhard Schmid (1872-1947). Księgozbiór prywatny ostatniego niemieckiego konserwatora zabytków w Malborku, Malbork 2011, s. $11-18$.

Sieradzan 2012: Wiesław Sieradzan, Związi ostatniego konserwatora zabytków Prus Zachodnich Bernharda Schmida (1872-1947) i jego rodziny z Grudziądzem, „Rocznik Grudziądzki”, 20, 2012, s. 203-222. 
SkIBIŃSKI 2011: Franciszek SkIBIŃskI, Konrad Graser Starszy i Johann Regius o kulcie obrazów. Przyczynek do dziejów sztuki w nowożytnym Toruniu, „Zapiski Historyczne", 76, 2011, z. 2, s. 7-16.

Skuratowicz 1991: Jan Skuratowicz, Architektura Poznania 1890-1918, Poznań 1991.

SMULIKowska 2005: Ewa SMulIKowskA, Korony i sukienki Obrazu Matki Boskiej Częstochowskiej jako przejaw kultu Królowej Korony Polskiej, „Studia Claromontana”, 23, 2005, s. 55-88.

SpIEż 2003: Jan Andrzej SpIEż, Początki klasztoru w Gdańsku na tle najstarszych fundacji dominikańskich, [w:] Dominikanie. Gdańsk - Polska - Europa, Materiały z konferencji międzynarodowej pt.: Gdańskie i europejskie dziedzictwo. Zakon dominikanów w dziejach Gdańska, red. Dariusz Aleksander DEkAŃskI, Andrzej GoŁembnik, Marek Grubka, Gdańsk-Pelplin 2003, s. 167-184.

Steinbrecht 1885: Conrad Steinbrecht, Thorn im Mittelalter. Ein Beitrag zur Baukunst des Deutschen Ritterordens, Berlin 1885.

Steinbrecht 1888: Conrad Steinbrecht, Die Baukunst des Deutschen Ritterordens in Preußen, 2: Preußen zur Zeit der Landmeister, Berlin 1888.

STRONER 1929: Władysław STRONER, O witrażu średniowiecznym w katedrze włocławskiej, „Prace Sekcji Historii Sztuki i Kultury Towarzystwa Naukowego we Lwowie”, 1, 1929, s. 71-93.

SzczypKa-GwIAzDA 2002: Barbara SzczypKA-GwIAzDA, Kwestia tożsamości sztuki ślaskiej $w$ polskim życiu artystycznym $w$ dwudziestoleciu międzywojennym, [w:] LIPOŃSKA-SAJDAK / SZCZYPKA-GWIAZDA / KRYPCZYK 2002.

Szyszka 2006: Maciej Szyszka, Romański kościół pod wezwaniem Świętego Mikołaja w świetle badań archeologicznych 2001, 2003 roku, [w:] Archeologia Gdańska, 1, red. Henryk PANER, Gdańsk 2006, s. 105-136.

Tomaszewski 1978: Andrzej Tomaszewski, Romańskie kościoły z emporami zachodnimi na terenie Polski, Czech i Węgier, Wrocław 1978.

Torbus 1998: Tomasz Torbus, Die Konventsburgen in Deutschordensland Preußen, München 1998.

Veldman 1992: Ilja M. Veldman, Images of labour and diligence in sixteenth-century Netherlandish prints. The work ethics rooted in civic morality or protestantism, „Simiolus”, 21, 1992, s. 227-264.

Veldman 2009: Ilja M. VeldMAn, Representations of labour in late sixteenth-century Netherlandish prints: the secularization of the work ethic, [w:] The idea of work in Europe from antiquity to modern times, eds. Josef EHMER, Catharina LIS, Farnham 2009, s. 149-176.

WAgner 2013: Arkadiusz WAgner, Nieznane cymelia introligatorstwa średniowiecznego w Bibliotece Uniwersytetu Mikołaja Kopernika, „Rocznik Biblioteki Narodowej”, 44, 2013, s. 177-210.

Walther / Wole 2005: Ingo F. Walther, Norbert Wole, Meisterwerke der Buchmalerei. Die schönsten Handschriften der Welt von 400 bis 1600, Köln 2005.

WARDZYŃSKI 2007: Michał WARDZyŃSKI, The import and use of Belgian marble and limestone in small architecture and stone sculpture on Polish territory from the Middle Ages to the second half of eighteenth century, [w:] Actes du XV Colloque International de Glyptographie de Cardoue, ed. J.-L. van Belle, Braine-le-Château 2007. 
WARDZYŃSKI 2008: Michał WARDZYŃSKI, Marmury i wapienie poludniowo-niderlandzkie na ziemiach polskich od średniowiecza do 2. pol. XVIII w. Import i zastosowanie w małej architekturze i rzeźbie kamiennej, „Biuletyn Historii Sztuki”, 70, 2008, nr 3-4, s. 307-357.

WARDZyŃSKI 2010: Michał WARDZYŃSKI, Import kamieni i dzieł rzeźby z Gotlandii i Olandii do Rzeczpospolitej (od XIII do 2. połowy XVIII w.), „Porta Aurea”, 9, 2010, s. 45-119.

WasIK 2012: Bogusz WasIK, Zabudowa zamku górnego i przedzamczy na podstawie źródeł pisanych i ikonograficznych z XVI-XVIII wieku, [w:] ZAMEK w GRUDZIĄDZU 2012, s. 57-71.

WasIK 2013: Bogusz WasıK, Architektura zamku w Kowalewie Pomorskim w świetle badań z 2013 roku, [mps], Toruń 2013 (dostęp - Instytut Archeologii UMK w Toruniu).

WasIK 2014a: Bogusz WasIK, Prace budowlane na zamkach w Grudziądzu i Toruniu u progu XIV wieku. Przyczynek do badań nad średniowiecznymi warsztatami budowlanymi w Prusach, „Rocznik Grudziądzki”, 22, 2014, s. 99-112.

WAsIK 2014b: Bogusz WAsIK, Analiza źródeł architektonicznych, [w:] ZaMEK BISKUPów w WĄBRzEŹnIE 2014, s. 87-98.

WasıK 2014c: Bogusz WasıK, Opisy wykopów badawczych, [mps], Toruń 2014 (dostęp Instytut Archeologii UMK w Toruniu).

WaSIK 2014d: Bogusz WASIK, Relikty architektury odkryte podczas badań archeologiczno-architektonicznych na zamku w Kowalewie Pomorskim prowadzonych w 2014 roku i wstępna analiza źródeł z nią związanych, [mps], Toruń 2014 (dostęp - Instytut Archeologii UMK w Toruniu).

Wentzel 1949: Hans Wentzel, Glasmaler und Maler im Mittelalter, „Zeitschrift für Kunstwissenschaft", 3, 1949, s. 53-62.

WisŁocki 2005: Marcin WisŁocki, Sztuka protestancka na Pomorzu 1535-1648, Szczecin 2005.

Zacharias 2000: Rainer Zacharias, Bernhard Schmid (1872-1947). Preußischer Landeskonservator und Baumeister der Marienburg, [w:] Das Preußenland als Forschungsaufgabe. Eine europäische Region in ihren geschichtlichen Bezügen. Festschrift für Udo Arnold zum 60. Geburtstag gewidmet von den Mitgliedern der Historischen Kommission für ost- und westpreußische Landesforschung, $\mathrm{Hg}$. Bernhart JÄHNIG, Georg MichELS, Lüneburg 2000, s. 689-714.

ZAMEK BISKUPÓw w WĄBRzEźNIE 2014: Zamek biskupów chelmińskich w Wąbrzeźnie. Studia i materiały, red. Marcin WiewióRA, Toruń 2014.

Zamek w Grudziądzu 2012: Zamek w Grudziądzu. Studia i materiały, red. Marcin WIEWIÓRA, Toruń 2012.

ZnAmierowsKa-PrüfeERowa 1977: Maria ZnAmIERowsKa-PrüEeERowa, Zabytki budownictwa ludowego $w$ Polsce $i$ ich rola we współczesnym krajoznawstwie $i$ turystyce, „Ochrona Zabytków”, 20, 1977, nr 4, s. 11-18. 